\title{
VILA RICA: A EPOPÉIA DAS MINAS
}

\author{
Sandra Mara Stroparo
}

RESUMO: Cláudio M. da Costa a écrit en 1772 un long poème intitulé "Vila Rica". Avec des prétensions épiques, l'auteur s'étend sur des références historiques et insiste sur la documentation, soit dans une longue introduction, soit dans des nombreuses notes ajoutées au texte. À la fin du XVIII ème, quand l'Histoire n'avait pas encore un discours autonome, le poète finit par construire un texte ambigu qui offre, cependant, l'intuition d'une identité.

PALAVRAS-CHAVE: literatura-história, Brasil do século XVIII, C. M. da Costa.

Considerado como um dos nossos expoentes poéticos, comparado por vezes aos seus contemporâneos europeus e disputado por Portugal com o fim de inseri-lo em sua História Literária, Cláudio Manuel da Costa é talvez o que de melhor pudemos produzir no século XVIII. Um único livro publicado em vida - Obras, reúne os melhores sonetos e éclogas, composições que deram e ainda sustentam a fama do autor que a si próprio nominou Glauceste Satúrnio.

Além de Obras, publicado em Coimbra em 1768, o autor deixou muitos outros textos manuscritos, incluindo revisões dos mesmos textos já publicados aos quais sempre parecia voltar. Há ainda uma série de sonetos atribuídos a ele, assim como a "Epístola a Critilo" que abre as Cartas Chilenas. Dentre os manuscritos, no entanto, não há texto mais controverso, não quanto à autoria, mas quanto à qualidade, que seu longo poema Vila Rica. Poderíamos fazer um levantamento curioso das observações críticas já feitas ao poema e que não lhe poupam adjetivos pouco elogiosos. Sílvio Romero, por exemplo, considera o lírico Cláudio Manuel da Costa um dos melhores dentre os mineiros, mas refere-se a este poema como "chato, prosaico, duro, inútil. (...) Como poesia é obra quase nula" (ROMERO, 1949, p.93). Sérgio Buarque de Holanda, por sua vez, considera que "prestaram um desserviço involuntário à memória desse poeta aqueles que zelosamente preservaram e os que mais tarde publicaram seu Vila Rica (...). Salva-o a presunção de que se trata de um esboço ainda informe que o autor não faria imprimir antes de melhorá-lo...” (HOLANDA, 1991, p.242).

Revendo a trajetória poética de Cláudio Manuel da Costa podemos perceber

Sandra Mara Stroparo é professora da UFPR. 
os embates entre uma natureza ainda barroca e as imposições de simplicidade e contenção do século, rejeitando a ostensividade da escola anterior: a verdade é que o arcadismo só alcançará o autor mineiro já no Brasil, após sua estada em Portugal, sendo que para apreendê-lo e segui-lo o poeta terá de dispor de um esforço de atualização que em alguns momentos de sua obra restou evidente. O seu poema épico será a melhor mostra disso: apesar da influência das epopéias clássicas ser claramente percebida, o autor alude a comentários teóricos de Voltaire no Essaie sur la poésie épique, e toma o seu La Henriade, poema épico de 1728, como parâmetro para um detalhe que lhe é caro: a fidedignidade histórica.

Alguns críticos enxergarão justamente nesta questão o momento da abertura literária - e pouco mais tarde política, propriamente - do autor às questões Iluministas. Plena de contradições, a historiografia do Século das Luzes oferece um primeiro passo ao que no século XIX vai finalmente começar a chamar-se História. No século XVIII, no entanto, embora o problema da veracidade dos fatos se confundisse com a intenção de racionalidade do discurso, os historiadores sujeitavam-se ainda a "regras da retórica e poética clássicas como metodologia da representação histórica" e a "uma suspeição simultânea da linguagem figurativa e do raciocínio analógico requeridos para a sua aplicação adequada" (WHITE, 1994, p.160). Ciente ou não de todas essas questões, Cláudio Manuel da Costa dá mostras de ter de alguma forma, solitariamente ou não, refletido sobre algumas delas.

Isso não se daria apenas em função das leituras realizadas mas também em razão do choque de sensibilidade que representava a cena literária arcádica com sua simplicidade e bucolismo de límpidos córregos, pacíficos pastores, rebanhos, prados e sombras de frondosas árvores e a realidade habitada, uma natureza rústica e exuberante, sem amenidades, a busca do ouro formando uma sociedade que dessa riqueza se constrói e através dela se vê explorada pela metrópole. Do ponto de vista poético, surgirá então a necessidade de uma epopéia: uma terra sem história ou tradição com mais dificuldade consideraria o seu momento presente.

A primeira tentativa, mais feliz inclusive, foi a "Fábula do Ribeirão do Carmo", em que um mancebo apaixona-se pela ninfa Eulina, consagrada a Apolo, e acaba transformado pelo deus no rio que banha a cidade de Mariana. Alguns anos mais tarde, bastante influenciado pela leitura do Uraguai (1769), de Basílio da Gama, o autor mineiro vai considerar a história das Minas e para ela criar musas e ninfas que lhe soprem versos sobre os nascimentos de rios e montes, desventuras de exploradores e a fundação de uma cidade. Poema de pretensões épicas, o Vila Rica narra a colonização das Minas Gerais pelos paulistas, os embates e a pacificação dos índios, as descobertas das riquezas e a fundação da Vila Rica de Ouro Preto. Escrito em 1773, é dedicado ao Conde de Bobadela, José Antônio Freire de Andrada, governador de Minas entre 1752 e 1761. O poema se compõe de dez cantos, uma Carta Dedicatória, um Fundamento Histórico e uma série de notas a todas estas partes, sendo esta uma das curiosidades do texto.

A sua tão discutida qualidade - ou a falta de - acaba por ser significativa se 
considerarmos as dúvidas e dificuldades existentes para o autor entre suas intenções de levantamento histórico e as possibilidades discursivas de que dispunha. Ao final acabou por construir um texto híbrido, entre a história e a poesia, e finalmente ambíguo em suas intenções.

"Não é meu intento sustentar que eu tenho produzido ao Mundo um Poema com caráter épico", afirma o autor no seu Prólogo ao leitor. Já aí coloca em questão a natureza do texto que oferece e a qualidade dele como pedia a modéstia literária: "tudo que não for injúria ou acusação será para mim uma inestimável remuneração das minhas fadigas". E já mesmo neste início começa a explicar-se:

"Se eu fiz alguma diligência por averiguar a verdade, digam-te as muitas Ordens e Leis que vês citadas nas minhas notas, e a extensão de notícias tão individuais com que formei o plano desta obra: pode ser que algum as conteste pelo que tem lido nos escritores da História da América; mas estes não tiveram tanto à mão as concludentes provas de que eu me sirvo; não se familiarizaram tanto com os mesmos que intervieram em algumas das ações e casos acontecidos neste País; e ultimamente não nasceram nele, nem o comunicaram por tantos anos como eu."

Note-se como se justifica, já além da própria documentação, a experiência do espaço e, até certo ponto, dos próprios fatos. Na parte que segue o Prólogo e a que o autor chamou de "Fundamento Histórico" novamente se explicam as fontes, fazendo alusões também à tradição e à memória de possíveis testemunhas. Percebe-se claramente não só a preocupação em convencer o leitor da veracidade das informações contidas na obra como também de que ela própria não dará conta de suas próprias intenções, por isso a longa exposição sobre os primeiros momentos colonizadores, as referências às fundações dos principais arraiais, à divisão das Comarcas, à série dos Governadores das Minas e por fim à descoberta das esmeraldas. Tudo isso é extensamente narrado no "Fundamento Histórico", ainda assim marcado por notas explicativas que acompanharão também todo o texto do poema propriamente dito, intensamente pontuado por citações, explicações e justificativas. De tal forma o autor serve-se de tantos complementos para sustentar o poema que por vezes no texto de alguma nota a referência se faz cruzada, enviando novamente o leitor ao "Fundamento Histórico"1 .

Mas o poema se inicia como pedem os clássicos: "Cantemos, Musa, a fundação primeira/ Da Capital das Minas, onde inteira/ Se guarda ainda, e vive inda a memória/ Que enche de aplauso de Albuquerque a história." Composto em decassílabos, com rimas emparelhadas, o poema vai obedecendo a propostas épicas ao anunciar não apenas o herói maior, aquele que em 1711 será responsável pela fundação de Vila Rica, mas também por aos poucos tratar de como foram os paulistas os responsáveis pelos primeiros arraiais, pelas primeiras descobertas das riquezas da terra e pela dominação dos índios da região.

A presença indígena no poema já foi lida como uma tentativa de inserção histórica do nativo americano na história do colonizador através do aproveitamento

${ }^{1}$ Veja-se por exemplo a nota 57, de um dos versos do Canto VII: (...) Tudo o mais se pode ver no Fundamento Histórico, em que fica elucidado esse Canto. 
de lendas e mitos que se mesclassem às considerações factuais e pudessem oferecer material poético à obra. Pertencendo à terra, pertenceria também ao índio suas histórias e através de algumas delas é que o colonizador português poderá conhecer e compreender os sucessos que lhe esperam. A sustentação lírica do poema, aparentemente mais extensa que suas pretensões épicas, se dará a partir da história amorosa da índia Aurora, narrada em "língua nacional, que não ignora" por sua mãe, a índia Neágua. Esse incidente servirá para nomear o lugar da primeira povoação das Minas, localizada junto ao "Rio das Velhas". Um pouco adiante a lenda do Itamonte - mais tarde Itacolomi - bastante calcada no canto $\mathrm{V}$ dos Lusíadas, que trata do gigante Adamastor, revelará aos portugueses os segredos e riquezas guardadas nas entranhas da terra.

Convivem no texto índios e brancos, paulistas e portugueses, algumas ninfas e o Curupira. Tais relações assim expostas serviram de justificativa para críticos como Antonio Candido e José Aderaldo Castello perceberem algumas características a que chamaram de nativistas. Aderaldo Castello será mais incisivo nesta proposta de leitura: "Quanto ao poema Vila Rica (...) não resta dúvida de que a sua elaboração definitiva resultou da plena definição crítica da atitude nativista do poeta. Convencido das solicitações do seu próprio sentimento - esse "amor da pátria" de que ele mesmo falava - o poeta decidiu-se, com certo orgulho, a exaltar um momento de nossa história (...)”. Já Sérgio Buarque de Holanda considerará a questão em direção oposta, defendendo o fato de que esta seria uma intuição moderna, impossível de ocorrer em Cláudio Manuel da Costa. Toma como exemplo uma das presenças supostamente necessárias ao nativismo, o localismo e a cor local, e afirma não haver nenhum contraste relevante entre a natureza idealizada, o locus amoenus de suas éclogas, e a natureza retratada em seu épico. Essa coerência, assim como um nacionalismo integral dotado de realismo serão detalhes fundamentais para os historiadores do século XIX e não poderiam existir em um poeta dos setecentos, especialmente como Cláudio Manuel da Costa, tão ligado em sua formação a um momento ainda anterior, Barroco e Neoclássico.

O suposto nativismo estaria ainda ligado a outras questões. A afirmação de que paulistas - e não portugueses - desbravaram as Minas é de substancial importância. O herói anunciado pode ser Albuquerque, o fundador de Vila Rica, mas é aos paulistas que se dará a verdadeira glória das descobertas, assim como serão eles os que arrancarão da terra as riquezas que enriquecerão a Coroa.

O gênio das "Pátrias Minas", Filoponte, revelará a Albuquerque a coragem dos conquistadores:

"Logo uns homens se vêem, que vão rompendo

Com intrépida força o mato horrendo,

Nus os braços e os pés, mas socorridos

Do necessário à vida: estão metidos

Por entre as feras, e o Gentio adusto;

Cada um de si só, perdido o susto,

Se embosca ao centro dos Sertões, se entranha 
Já pelo serro, já pela montanha;

Uma e outra distância gira em roda,

E deixa descoberta a extensão toda.

A presença dos negros:

Passa este quadro, e logo outra pintura

Nova imagem propõe, nova figura,

Que retrata uns mortais de negras cores,

Regando o aflito rosto de suores

À força das fadigas com que cavam

As brutas serras, e nos rios lavam

As porções extraídas, separando

As pedras do metal, que andam buscando."

E a expulsão dos paulistas - sendo estes chamados de conquistadores - pelos portugueses, fato que se deu entre os anos de 1709 e 1710:

"Eis que outros homens de semblantes feros

Contra os Conquistadores já severos

Os fazem despejar desde os seus lares;

Disperso o sangue se recolhe em mares;

Família, e armas, cabedais, e tudo

Cede aos avaros, que do ferro agudo

Fazem despejo à fugitiva gente." 2

Em trechos como esses, assim como em outros momentos do poema, percebemos a queixa do mazombo, o descendente de portugueses já nascido no Brasil, em relação ao colonizador. Com a presença do corajoso Manuel de Borba Gato em sua expedição, Albuquerque assiste a uma disputa entre portugueses e paulistas que altercam a dita valentia daqueles à já provada força e coragem destes. Afirma um dos portugueses:

"Que ao valor europeu em pouco ou nada

Disputar do Paulista pode a espada."

Note-se o detalhe de estar "Paulistas" grafado com inicial maiúscula, ao contrário de "europeus". Ao que responde, com "furor ardente", o bandeirante:

"Se ao Paulista de fraco alguém acusa,

Ele de seus espíritos só usa,

Quando a honra do empenho ao campo o chama.

Não é valente, não, o que se inflama

No criminoso ardor de a cada instante

Dar provas de soberbo, e de arrogante.

Os Europeus são fáceis neste arrojo.

Se justo imaginais foi o despojo

Das Minas, que lhes tiram, porque avaros

Se pertendem mostrar (bem que são raros

Os que entre eles se arrastam da cobiça),

${ }^{2}$ Estrofes pertencentes ao Canto V. 
Dizei: não pede a próvida Justiça

Que zele cada um, que guarde, e reja

O que adquire o seu braço, quando a inveja

Lho pertende roubar? Estas conquistas,

A quem se deverá mais que aos Paulistas?

(...)

Acaso um mesmo Rei não nos protege?

Uma só lei não nos rege?

Do tronco português não é que herdamos

O sangue de que as veias animamos?

Não faz comuas um Vassalo as glórias

Do seu Rei? Do seu Reino? (...)

(...) não alcança

A todos o infortúnio e a bonança?

(...)

Do Europeu, do Paulista faço apreço,

E distinguindo em todos a virtude (...)

Não faz a Pátria o Herói, nascem de Aldeias

Almas insignes, de virtudes cheias;

E nem sempre na Corte nobre e clara

Ingênua série, portentosa e rara

Se vê de corações, que resplandescem

Pela glória somente, e nela crescem"3 .

Rouba-se novamente de Albuquerque o verdadeiro lugar do herói na epopéia e encontra-se no bandeirante paulista uma das mais belas falas do poema, plena de equilíbrio e sensatez, algumas das principais virtudes do herói clássico, ao mesmo tempo em que reivindica, invocando a Justiça, a glória aos seus verdadeiros merecedores. Com certa freqüência ainda o poema apresentará o ouro da terra simultaneamente como fonte de riqueza e desgraça, a alegria do nascimento da Pátria trazendo consigo a chaga da ganância gerada pela mineração.

Certamente não podemos aqui nos referir a uma idéia de nativismo e pátria como a que será mais tarde elaborada e defendida pelos românticos num país já oficialmente independente da Metrópole. É possível atentar, no entanto, ao fato de que a defesa veemente dos paulistas e a condenação velada às atitudes portuguesas já significam, ao menos, a defesa da "aldeia". Freqüentemente no texto, desde a "Carta Dedicatória", o autor se refere às Minas como seu berço e Pátria e embora esse conceitos não estejam ainda nesse momento propriamente servidos do caráter emocional e ufanista que encontraremos no século XIX e mesmo no século XX, eles demarcam, contundentemente, diferenças e distanciamentos que opõem colonizadores e colonizados.

Se houve realmente, na sua origem, a intenção de evidenciar no texto a queixa do colono dirigida ao reinol, o que podemos considerar é que a natureza incerta do

${ }^{3}$ Estrofes pertencentes ao Canto VII. 
poema, que nem épico quer ser, transitando entre relato e documentação histórica, atmosferas míticas com personagens mágicos e metamorfoses clássicas parece ter servido para expressar as próprias dúvidas, queixas e, a essa altura, aparente decadência da veia poética do autor. Seria ainda um exagero querer encontrar aí as intenções de um cabotinismo político, tão evidente e bem resolvido nas Cartas Chilenas de Tomás A. Gonzaga. Mas podemos enfim, sem sermos demasiado destruidores ou idealizadores, relevar que ao chamar aos Paulistas claramente de "Conquistadores" e aos Europeus, embora arrevezadamente, de soberbos e arrogantes, o autor marcava uma posição menos idealizada inclusive que a dos próprios Românticos que o seguiram. Talvez esse caráter rebelde do texto justifique, mais que a pouca qualidade, o fato de o autor nunca o ter editado e ao mesmo tempo o interesse sempre despertado pelo poema, comprovado pelos inúmeros manuscritos do poema que transitaram em Vila Rica, antes e depois da Devassa.

\section{BIBLIOGRAFIA}

CANDIDO, Antonio. Formação da Literatura Brasileira. Belo Horizonte, Itatiaia, 1981.

CASTELLO, José Aderaldo. Manifestações Literárias da Era Colonial. São Paulo, Cultrix, 1967.

COSTA, Cláudio Manuel. Vila Rica. In: PROENÇA Fo, Domício (org.) A poesia dos Inconfidentes. Rio de Janeiro, Nova Aguilar, 1996.

HOLANDA, Sérgio Buarque de. Capitulos de Literatura Colonial. São Paulo, Brasiliense, 1991.

ROMERO, Sílvio. História da Literatura Brasileira. Rio de Janeiro, José Olympio, 1943. 